\title{
Research on Integration of Information System in Customs Supervi- sion Warehouse Based on Business Process Improvement
}

\author{
Han Chengguo ${ }^{1+}$, Guanwei Jang ${ }^{1}$, Zhao Jiuxian ${ }^{2}$ and Qin Shilin ${ }^{3}$ \\ ${ }^{1}$ Guangdong University of Science and Technology, China \\ ${ }^{2}$ Shenzhen GuanYunTong Technology Co., Ltd, China \\ ${ }^{3}$ Shenzhen YourSender Supply Chain Group Co., Ltd, China
}

\begin{abstract}
With the rapid development of China's import and export trade, customs supervision warehouse is facing the pressure of order surge, fragmentation and complex commodity SKU, which affects the operation efficiency and error rate. This paper comprehensively investigates and analyzes the three core processes of customer appointment, goods in and out of warehouse and customs declaration. Taking YanTian warehouse in Shenzhen of X supply chain company as an example, based on commodity master data management and unified management of appointment form, customs declaration form and goods information of in and out of warehouse, to simplify the operation process and reduces duplicate data entry. Through the establishment of an integrated and unified warehouse information system, the integration of customer appointment, WMS and customs declaration system, to ensure the accuracy of the data and information of goods in and out of the warehouse and the efficient operation of the whole process, and promote the intelligent and digital upgrading of the information operation of Customs warehouse management.
\end{abstract}

Keywords: Business Process Improvement, Core Process, Master Data Management, Information Integration System

\section{Introduction}

The customs supervision warehouse generally refers to the warehouse type supervision places that are mainly used to store the import and export goods that have not been declared and released, and these places meet the requirements of the customs [1].In the customs logistics supervision system, the customs supervision warehouse management plays an important role, which has a far-reaching impact on the followup supervision operations of customs, such as arrival report verification, manifest management and so on. It provides basic data and information sources for customs clearance and inspection, including goods in stock information - goods name, classification, quantity, etc. It is of great practical significance to optimize the operation process of customs supervision warehouse and improve the informatization level of customs supervision warehouse for improving the customs supervision system and improving the efficiency of logistics clearance.

With the rapid development of China's import and export trade, the import and export goods of general trade and cross-border e-commerce are characterized by fragmentation of orders, diversification of product names and sharp increase of goods volume. The traditional customs supervision mode of warehouse and warehouse operation are facing great pressure, mainly in the following three aspects:

1. The source of information needs a lot of manual input, which is slow and has a high error rate. There are some problems such as asymmetric information between WMS of supervision warehouse system and the customs single window [2], and the data interaction is not timely;

2. Due to the limited manpower of the customs, the informatization level of warehouse management under customs supervision is low, the workload of manual supervision is heavy, and the efficiency is low;

\footnotetext{
+ Corresponding author. Tel.: + 18611822218; fax: +(0769)86211800..

E-mail address: $1819777573 @ q q . c o m$.
} 
3. There are some problems in the warehouse under the supervision of the customs, such as poor integration of the goods in and out process and customs declaration process, repeated manual operation, high error rate, lack of information integration and so on;

The main goal of this paper is to sort out the whole process of goods in and out of the warehouse under customs supervision, establish a unified master data management of goods, and eliminate the duplication of manual entry in the three core processes of customer appointment, goods in and out of warehouse and customs declaration. Through the establishment of integrated and unified supervision warehouse information system, the integration of customer appointment, WMS and customs declaration system, the frequent import and export goods warehousing and customs declaration can be quickly completed, he efficiency of warehouse operation and customs supervision can be improved, and the intelligent and digital upgrading of warehouse management information operation under customs supervision can be promoted.

At present, according to the requirements of customs supervision, scholars at home and abroad carry out research in the fields of customs declaration, warehouse management, customers and customs system involved in the whole process of warehouse supervision. Peng Shoumin and Cui Yan analyzed and studied the customs cargo clearance process from the aspects of process discovery, process modeling, process simulation and process monitoring, and proposed the graphical modeling and simulation optimization method of customs cargo clearance process based on BPM, and the implementation and monitoring method of executable process model [3]. Shi Wenqian clearly put forward that the customs should be included in the operation and management of enterprises, making the customs change from "managing enterprises" to "managing processes" [4]. Jiang Jian's research showed that in oder to promote the competitiveness of local exporters, it is more conducive through the shift of focus on goods supervision from middle term to pre-term or post-term of supervision on enterprises [5].Zhang yinfen studied the standardization construction and application of single window in international trade, and standardized the data collected by relevant trade authorities, which not only meets the requirements of enterprises submitting data at one time, but also meets the international standards, and can meet the needs of data exchange with other countries or international regional organizations [6].

\section{Analysis of the Status quo of Process and Information System}

This paper focuses on the customs supervision warehouse of $X$ supply chain company, the largest package delivery company in the world, in Yantian, Shenzhen, China (hereinafter referred to as X warehouse).The total area of $\mathrm{X}$ warehouse is more than 20000 square meters, which provides comprehensive services such as storage of import and export goods, value-added processing and customs declaration for customers in Great Bay district. Through the online appointment system for import and export goods of $\mathrm{X}$ warehouse , customers can make appointment application for the required goods in and out of warehouse in advance , After the customs declaration Department of $\mathrm{X}$ warehouse prepares the customs declaration data through the customs declaration system and makes internal audit, it uploads them to the customs single window. After the customs approves and releases them, $\mathrm{X}$ warehouse shall carry out warehouse in and out operations and inform customers to cooperate with relevant procedures. Taking a customer's imported printer accessories as an example, the whole process scenario is shown in Fig. 1. From the perspective of customs supervision, we should pay attention to the information in warehouse $\mathrm{X}$ and the customs account system, including the quantity, unit price, volume and weight of the goods. The customs can check the consistency between the declaration information of a certain batch of goods or a certain ticket and the actual operation of the warehouse at any time.

Through our in-depth research, the main process of $X$ warehouse operation is composed of three core sub processes: customer appointment, customs declaration and warehousing operation. The master data management of customs declaration elements such as commodity, customer, tax rate and entry-exit port is the link and data exchange foundation of the three sub processes. Taking commodities as an example, the commodity data provided by customers when they make an appointment are enterprise ERP self coding and self defining commodity names. The warehouse department of the supervision warehouse also has its own classification standards and naming rules for commodity management. However, the customs declaration Department of the supervision warehouse manages the commodities in the import and export warehouse according to the customs declaration catalogue of the customs of the people's Republic of China, and makes declaration 
according to the format required by the customs .According to the regulations of the customs of the people's Republic of China on the registration and administration of customs declaration units (Order No. 221 of the General Administration of Customs in 2014), non-compliance with the requirements of commodity standard declaration will be recorded as a declaration error, which will affect the AEO qualification certification of customs declaration and the export tax rebate of customers in the warehouse under supervision [7].Therefore, unified management of customer and warehouse commodity master data, according to the customs specification catalog is the basis of process optimization. The current situation of $\mathrm{X}$ warehouse is that there is no restriction on the definition rules of customers' goods when customers make an appointment. The warehouse department and customs declaration Department of the regulatory warehouse use WMS system and customs declaration system to manage goods respectively, and maintain the data consistency between the two systems through Excel import and manual modification. All of the above have seriously affected the real-time and refinement of the customs warehouse management.

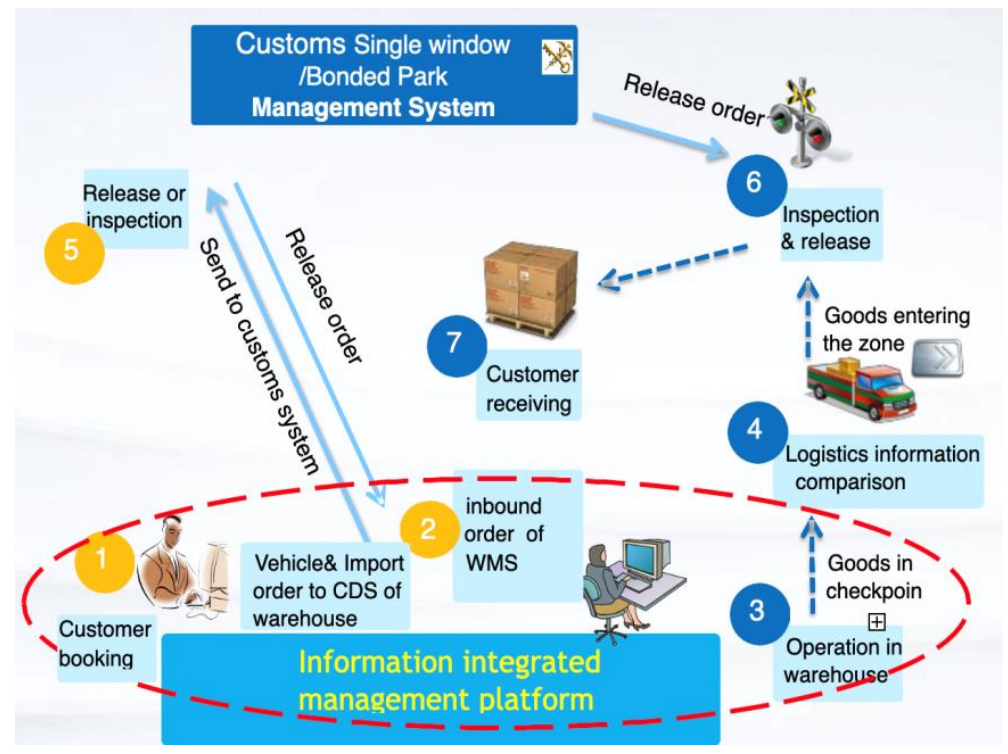

Fig. 1: Import process of $\mathrm{X}$ warehouse

\section{Process Improvement Method and Implementation}

From the above analysis, we can draw the conclusion that the core principle of process optimization is to conform to the customs' management standard of goods in supervised warehouses. Based on the business process optimization (BPI) theory proposed by Dr. hammer, this paper focuses on eliminating non value-added activities, simplifying necessary activities, integrating tasks and process automation [8].

The first step is to make it clear that "make an appointment first, pass the customs declaration and then carry out the warehousing operation", so as to reduce the repeated labor of receiving and sending goods and warehousing operation caused by the goods not conforming to the customs supervision and failing to pass the declaration. The customer appointment sub process is initiated first, and the appointment form is transferred to the customs declaration sub process. The customs broker in the supervision warehouse classifies the goods and makes the declaration form according to the appointment data. After internal review, the system is connected and uploaded to the customs single windows system for review. The customs returns that the declaration form is in the "release" status, and the customs broker informs the storage department of the supervision warehouse to give the customer "vehicle reservation" The customer is informed that the vehicle enters the supervision warehouse, and then the sub process of warehouse entry and exit is carried out. The data of goods in and out of the warehouse enters the WMS and is transmitted to the customs data center through the interface. The Customs checks the data of the supervised warehouse logically to ensure that the physical data of the warehouse and the customs declaration data are strictly matched. If a ticket declaration is controlled and inspected by the customs, the customs single window will transfer the inspection requirements to the customs declaration system of the supervised warehouse, and the customs declarant will arrange the warehouse personnel and the customs declaration field to cooperate with the customs inspection. This inspection notice will also be fed back to the customer through the customer appointment system. The second aspect of the optimi- 
zation of the warehouse supervision process is that the key information in the customer appointment form, customs declaration form and warehouse entry / exit form is unified according to the "Declaration catalogue of import and export commodities of the customs of the people's Republic of China". The position of "commodity classification specialist" in the customs declaration sub process is put in front of the customer appointment sub process to sort out the historical data of long-term cooperative customers and establish the master data management database according to the customs commodity declaration directory. When customers fill in the appointment form, they must select from the master database. If there are new commodities, they should contact the "commodity classification specialist" to standardize the classification and update to the database. The specialist will also pay attention to the information on the official website of the General Administration of customs and update the main database timely The warehouse in and out sub process is also based on this main database to manage goods and update the inventory system data . In this way, as shown in Fig. 2, the main process of supervision warehouse management realizes the unification of master data, and avoids repeated data entry and disconnection of various systems.

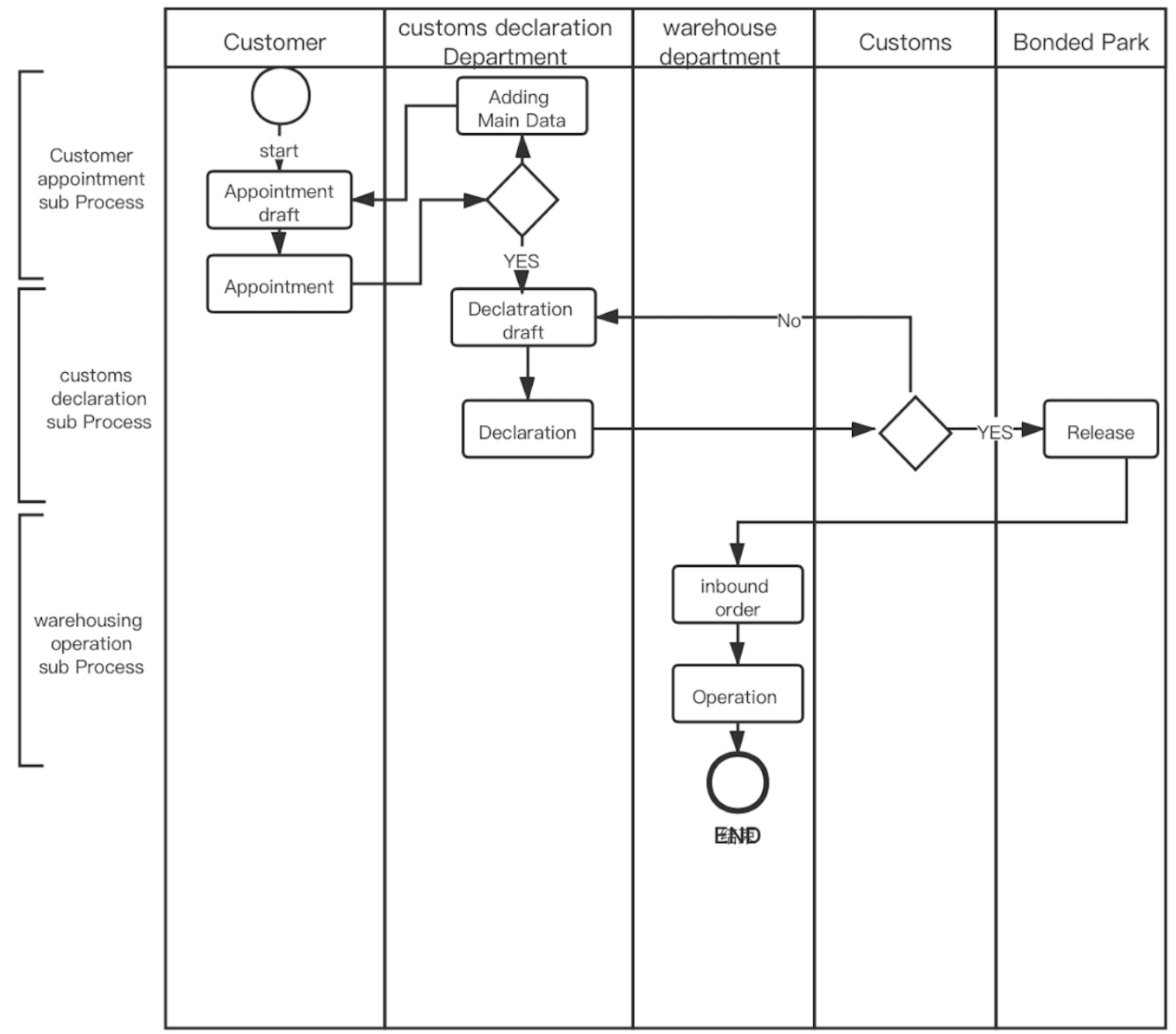

Fig. 2: Business Process Modeling Notation of $\mathrm{X}$ warehouse

\section{System Integration Solution}

According to the above analysis and optimization principles for the whole process of import and export operation of supervision warehouse, the framework of integrated information system of supervision warehouse can be planned, as shown in Fig. 3. 


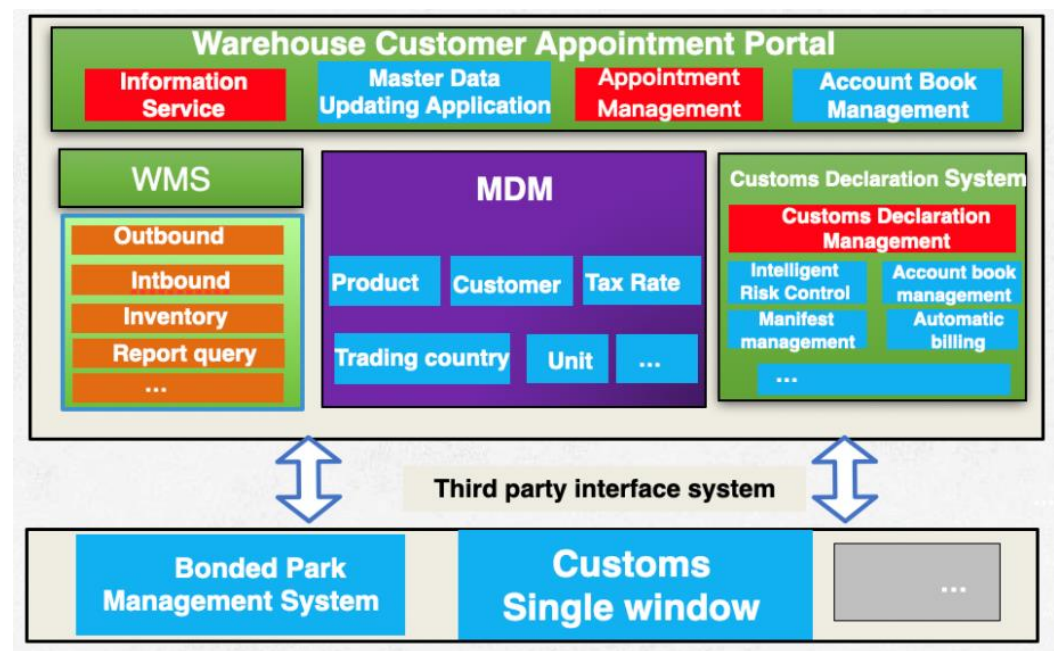

Fig. 3: Framework of integrated information system for $\mathrm{X}$ warehouse

This system includes four modules: appointment portal, WMS system, customs declaration system and master data management. The master data management module unifies the basic data of commodities, customers and tax rates. Customers can make appointment and information query through mobile client or PC appointment portal. Through this portal, the commodity classification specialist of supervision warehouse interacts with customers. For example, when new commodities are added, the commodity classification specialist will update in the master data management module according to the commodity information provided by customers and referring to the customs commodity management specifications. WMS system and customs declaration system are integrated seamlessly to ensure that the warehouse physical operation and customs declaration information are in accordance with each other [9].

The integrated information system of supervision warehouse provides the information required for supervision to Shenzhen customs data sub center through the interface of WebService or HTTP restful API system. The specific format can refer to the XML document of standard document for WMS interface format of Warehouse Enterprise (Reference), so as to facilitate the customs to monitor the whole process data of the supervision warehouse.

\section{Implementation Effect and Future Research Trend}

The process improvement and integrated system construction of supervision warehouse bring good economic benefits and competitive advantages for enterprises. Taking $X$ warehouse as an example, the value return is mainly reflected in the following three aspects:

1. Master data unified management, reduce the error rate of customs declaration and warehouse operations. In 2020, there are more than 30000 declaration forms, and the number of wrong declaration forms is less than 5 , which is $50 \%$ lower than that before process optimization

2. With the integration of information, the work efficiency of warehouse staff is improved, and the customs supervision is transparent. In 2020, the customer booking time and customs declaration time of warehouse $\mathrm{X}$ have been reduced by $10.79 \%$ and $15.51 \%$ respectively.

3 . Due to the reduction of repeated data entry and manual workload, the number of document processing personnel is reduced from 15 to 12 , and the labor cost is reduced by $20 \%$.

Based on the needs of China's customs supervision and the development of import and export trade, the function expansion of the integrated information system of the supervision warehouse is mainly in two aspects. The first is to realize the customs unmanned supervision, and introduce technologies such as highdefinition monitoring, face recognition and 5G. The second is the application of artificial intelligence in the fields of customs declaration document processing and image recognition in the regulatory warehouse. For example, through natural language processing and semantic analysis based on the knowledge map of commodity declaration elements [10], it can realize automatic commodity classification [11], improve the production efficiency of customs declaration and reduce human errors. 


\section{References}

[1] Department of supervision and control of the General Administration of customs. Customs practice of China [M]. Beijing: Customs press, 2015

[2] Bai Jianjun. Building "single window" to realize information sharing [J]. China Port Science and Technology , 2019 (4) :20-21

[3] Peng Shoumin, Cui Yan. Simulation and optimization of port clearance process based on BPM [J]. Science and fortune, 2011 (1):27-28

[4] Shi Wenqian. Research on warehouse process optimization of bonded warehouse of $X$ company [D]. Nanjing: Nanjing Normal University. 2019

[5] Jiang Jian. Research on Chinese Customs Supervision System under China's New Round of Reform and Opening Up [D]. Beijing: University of International Business and Economics . 2017

[6] Zhang Yinfen. Implementation Guide for single window of international trade [M]. Beijing: Electronic Industry Press, 2015

[7] Hu Rong. National Research on supply chain security and customs supervision system [M]. Shanghai: Shanghai People's publishing house, 2020

[8] Shui zangxi. Process optimization and reengineering, Third Edition [M]. Beijing: China Economic Publishing House, 2013

[9] Han Chengguo, Zhao Lindu, Feng Wei. Research on information construction of supply chain enterprises under the new circulation reform[J]. Computer era, 2019 (4):103-106

[10] Cheng Cun. Research on classification and recognition algorithm of container cargo X-ray perspective image [D]. Beijing: Tsinghua University. 2019

[11] Wang Hao. Research on the intelligence value and utilization of government data in big data environment--Taking the risk aversion of commodity classification in customs declaration as an example[J].Scientific Information Research,2020(10):74-89 